\title{
KAJIAN HADIS-HADIS ETIKA MAKAN DITINJAU DARI ASPEK KESEHATAN
}

\author{
Zeid B. Smeer \\ Fakultas Humaniora dan Budaya Universitas Islam Negeri Maulana Malik Ibrahim \\ Malang Jalan Gajayana 50 Malang 65114 Telp. (0341) 551354 HP. 08123368707 \\ e-mail: zeidsmeen@gmail.com
}

\begin{abstract}
Islamic teaching has a lot of meaning and wisdom. There are no obligation and restriction which has no message, benefit, and wisdom. Some of the benefits and wisdoms have been known and understood, some have not yet. This must motivate each Muslim to continuously study the hidden secret including studying the ritual practices which is for the time being viewed as the Islamic traditions such as the eating ethic. This research intends to know the wisdom containing in the Hadith of eating ethics taught by the Prophet Muhammad through hismessage seen from heal th aspect. This research is library research which initially collecting the Hadith on eating ethic, then, exploring relevant information from classical and modern books dealing with health. Exploring also the textbooks on health and health practitioners are investigated. The finding is the eating ethic taught by the Prophet Muhammad through his Hadith has a lot of beneficial wisdom and it has been justified by the experts.
\end{abstract}

Key words: eating ethic and health

\section{Pendahuluan}

Rasulullah SAW. mengajarkan banyak hal yang bermanfaat bagi umatnya, sebagaimana tertulis dalam hadis-hadisnya. Ajaran- 
ajaran tersebut hingga kini sudah banyak dikaji dan dipelajari. Misalnya kajian hadis-hadis ibadah yang dilakukan oleh Teguh Imanullah tentang khasiat shalat dari aspek kesehatan (Teguh, 2006: 12), kajian hadis dalam tesis Mashudi tentang Konsep hadis tentang pembinaan Akhlak, dan lain sebagainya. Namun pengkajian hadis dari sisi pemaparan hikmah dan rahasia tampaknya belum banyak dilakukan (Mansur, 2004: 45 ).

Dalam kitab-kitab hadis, para ulama mengelompokkan ajaranajaran atau hadis-hadis Rasul tersebut dalam bab-bab tersendiri. Misalnya hadis-hadis tentang ibadah, akhlak, muamalah, hidup bertetangga, hubungan suami istri, bersuci, etika makan dan minum, yang kesemuanyaitu menunjukkan kepedulian Rasulullah SAW. pada umatnya.

Pesan Rasulullah SAW. bukanlah pesan yang kosong dari hikmah dan manfaat, tidak sebatas etika yang berkaitan dengan adat istiadat, namun sebaliknya, pesan itu sarat dengan ajaran dan tuntunan yang mengandung makna yang begitu dalam. Hal iu dikarenakan segala apa yang disampaikan dan prilaku Nabi bersumber dari wahyu ilahi, sebagaimana tertera dalam QS. al Najm: $3-4$

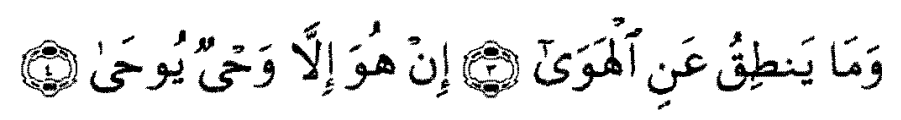

Dalam sebuah riwayat Rasulullah SAW. dengan tegas menyuruh seorang sahabat untuk menulis apa yang beliau katakan, karena yang beliau katakan mengandung kebenaran. Ucapan beliau ini sebagai bantahan terhadap seorang sahabat yang ragu akan ucapan beliau yang mungkin mengandung kesalahan karena beliau adalah manusia biasa. Contohnya masalah muamalah yang diatur sedemikian rapi, masalah silaturrahmi, masalah kesehatan, termasuk juga etika makan dan minum, yang kesemuanya itu sarat dengan makna dan faedah. Bahkan telah terdapat beberapa kajian tentang hal tersebut yang nembuktikan kebenaran ucapan Rasulullah SA viv. 
Khusus masalah kesehatan, banyak hadis yang mengisyaratkan hal itu. Buku karya ibnuu Qayyim al Jauzi al Thib al Nabawi adalah salah satu buku yang berusaha mengkaji hadis-hadis Nabi secara mendalam dari aspek pengobatan. Paling tidak, buku ini ingin membuktikan bahwa ajaran Nabi SAW. tidak kosong dari bidang kedokteran.

Tidak kurang dari 80 metode pengobatan dan terapi kesehatan yang telah dipaparkan oleh ibnu Qayyimdalam kitabnya, yang kesemuanya bersumber dari hadis-hadis Nabi SAW. Misalnya: pengobatan penyakit mata, gatal-gatal, bisul, pencernaan, step, pendarahan, dan keracunan. Metode pengobatan tersebut juga telah banyak dipraktikkan dan dibuktikan kebenarannya secara ilmiah oleh banyak orang yang berkompeten dalam bidang kedokteran.

Jauh sebelum itu, para sahabat Nabi juga pernah melakukan pengobatan melalui ruqyah dengan menggunakan surat al Fatihah yang ditiupkan di air dalam gelas guna menyembuhkan orang yang terpatuk ular sebagaimana diriwayatkan dalam kitab Shahih alBukhari (al Asqollani, 1990: hadis 4623). Pengobatan serupa memang telah populer dilakukan oleh generasi pendahulu kita.

Sosok ibnu Sina tidak akan pernah terlupakan dari ingatan kita, muslim maupun non-muslim. Nama beliau cukup tershohor di dunia kedokteran, dan tidak dapat dipungkiri, bahwa sebagian praktik pengobatan ahli kedokterran dan sekaligus filosof ini bersumber dari ajaran Islam.

Penelitian ini ingin mengkaji makna yang terkandung dalam hadis-hadis etika makan, dari mulai posisi duduk, cara makan, porsi makanan, dan beberapa anjuran lain yang terkait dengan tata cara makan sebagaimana terdapat dalam hadis-hadis Nabi ditinjau dari aspek kesehatan. Namun, pembahasan dibatasi pada hadishadis etika makan yang dapat dikaji dari aspek kesehatan yang berjumlah sekitar 15 (lima belas) Hadis dari sumber 9 kitab hadis (al Kutub al Sittah).

Penelitian ini dinilai penting, karena dengan penelitian ini diharapkan akan dapat menemukan hikmah-hikmah dari anjuran 
Rasulullah SAW. yang selama ini masih dinilai sebagai masalah budaya dan kebiasaan lokal (al 'adah al mahaliyah) atau dikategorikan amrun ta'abbudi.

Pendekatan yang digunakan juga dikaitkan dengan aspek fisiologi manusia, khususnya yang berkaitan dengan proses pencernaan, karena bidang inilah yang diharapkan dapat mengungkap makna yang terkandung dalam hadis-hadis Rasul tentang etika makan tersebut.

Fisiologi merupakan bidang ilmu yang berkaitan dengan fungsi faal organ tubuh, baik manusia, hewan maupun tumbuhan. Namun, dalam penelitian ini peneliti menggunakan fisiologi manusia sebagai pendekatannya. Fisiologi mempelajari fungsi atau kerja tubuh manusia dalam keadaan normal. Ilmu ini sangat erat kaitannya dengan pengetahuan tentang semua makhluk hidup yang tercakup dalam pelajaran biologi (Pearce, 1996: 1).

\section{Etika Makan dalam Perspektif Hadits}

Ilmu kesehatan modern menjelaskan bahwa, untuk mengetahui masalah-masalah kesehatan dan sakit dengan tepat, yang perlu dikaji adalah struktur dan fungsi manusia sehat, serta berbagai kemungkinan penyimpangan, mulai dari tingkat manusia utuh hingga tingkat sub-seluler secara benar. Bidang ini adalah tugas pakarpakar di bidang ilmu Anatomi, Histologi, Fisiologi Kedokteran, Biokimia, Mikrobiologi Kedokteran, Parasitologi Kedokteran, Patologi Anatomi, Patologi Klinik, Farmakologi, Farmasi Kedokteran, Ilmu Gizi Kedokteran, dan lain-lain.

Selanjutnya, untuk memahami dan mengetahui dengan baik teori dan konsep yang berhubungan dengan penyimpangan fungsi sistem organ/ penyakit, dan pengelolaannya, dalam bentuk metode atau teknik medis adalah tugas pakar-pakar di bidang ilmu terkait dalam bidang Ilmu Bedah. Ilmu Penyakit Dalam, Ilmu Kesehatan Anak, Ilmu Kebidanan dan Kandungan, Ilmu Penyakit Mata, Telinga, 
Hidung, dan Tenggorokan, Ilmu Penyakit Jiwa, dan lain-lain (Fakultas Kedokteran UII, 2002: 11).

Dalam ajaran Islam, kesehatan dipandang sebagai rahmat Tuhan yang sangat besar. Banyak nash agama yang menekankan agar manusia menjaga kesehatannya, menghindari penyebab yang dapat mengakibatkan sakit. Banyak faktor yang menyebabkan datangnya penyakit, di antaranyakarena 'salah atur' dalam masalah makan, minum, dan berbagai aktivitas yang berhubungan dengan fisik, seperti tidak menjaga kebersihan, mengabaikan saran medis, dan kurang berolahraga.

Menjaga kesehatan merupakan masalah penting dalam kehidupan insani. Sudah menjadi semacam kesepakatan, bahwa menjaga agar tidak terkena penyakit adalah lebih baik dari pada mengobati, bahkan ruh hukum Islam banyak disemangati prinsip ini (Ali, 1994: 258, 264, 433). Syariat Islam menekankan agar umat Islam menjaga kesehatannya sebagai dicontohkan Nabi SAW, juga tergambar dalam doa-doa serta anjurannya memohon kesehatan yang hakiki dan abadi, meliputi kesehatan jasmani dan rohani, dunia dan akhirat, kesehatan di berbagai bidang kehidupan yang meliputi agama, kehidupan duniawi, keluarga dan harta.

Perhatian Islam terhadap masalah-masalah yang berkaitan dengan kesehatan dapat pula digali dari berbagai praktik ubudiah dari sisi hikmah al tasyri', di samping sebagai tuntutan syariat, juga terbukti bernilai sebagai bentuk menjaga diri dari penyakit lahir dan batin. Penggalian hikmah al tasyri' dari segi maslahah, mafsadah, serta madharrat terhadap suatu perintah atau larangan agama, ada kalanya sudah jelas makna dan tujuannya, namun adapula yang menjadi jelas setelah diteliti dan digali hikmahnya. Banyak masalah dalam agama yang selama ini dikatakan sebagai amrun ta'abbudi karena tidak diketahui hikmahnya, tetapi pada masa-masa selanjutnya hikmah tersebut terungkap, hingga persoalan tersebut tidak lagi menjadi amrun ta'abbudi.

Pola makan yang baik dan teraturditekankan dalam al Quran, misalnya anjuran memperhatikan makanan (Q.S. Abasa: 24), makan 
secara proposianal dan tidak berlebih-lebihan (Q.S. al-A'raf: 31). Anjuran makan dan minum secara proposional dalam al Quran diungkapkan misalnya dengan kata 'wala tusrifu', memiliki pengertian yang amat dalam dan luas. Ali ibnu Husain ibnu Waqid (Suyuthi, 1997: 22), menyatakan bahwa Allah SWT. menempatkan semua obat pada separuh ayat ini. Ayat ini oleh ahli pengobatan Islam di masa awal dikategorikan sebagai ayat kedokteran. Pengategorian ini muncul berdasarkan pertanyaan yang diajukan kepada ahli pengobatanIslam pada saat itu. Mereka ditanya, apakah dalam al Quran ada dalil tentang kedokteran? Mereka menjawab, "ada", Allah telah menghimpunnya dalam kandungan ayat 31 dari surat al A'raf.

Ibnul Qayyim rahimahullah membagi tingkat makanan menjadi tiga tingkatan:

1- Tingkat kebutuhan: yaitu seperti yang dijelaskan oleh Rasulullah shallallahu alaihi wa sallam.

"Cukuplah bagi manusia untuk mengkonsumsi beberapa suap makanan saja untuk menegakkan tulang rusuknya." Jika tidak mampu menahan dirinya untuk menkonsumsi lebih maka ia berpindah ke tingkat berikutnya yaitu

2- Tingkatan cukup: yaitu mengisi sepertiga perutnya untuk untuk makanan, sepertiga untuk minuman dan sepertiga untuk bernafas, dan hikmah dibalik itu dikarenakan perut kita mempunyai kapasitas yang sangat terbatas dan jika semuanya dipenuhi dengan makanan maka tidak ada tempat lagi untuk minum dan sulit benafas.

3- Tingkat berlebihan: tingkat ini bisa membahayakan dirinya tanpa ia sadari. Hal ini banyak kita alami, dan kebanyakan orang yang terjangkit penyakit gula, depresi, kegemukan, jantungan dan struke tidak lain adalah disebabkan mereka tidak mengatur pola makan dengan baik, serta berlebihan dalam makan dan minum.

Syekh Muhammad al Ghazali membagi etika makan menjadi tiga bagian, yaitu: 1) Hal-hal yang dilakukan sebelum makan (قبـل 


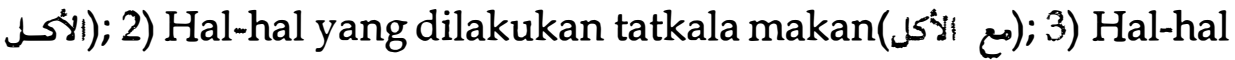
yang dilakukan setelah makan (بعـد الأكسل)

Dalam konteks kesehatan banyak ditemukan petunjuk tersebut dalam al Quran dan Hadis. Berikut ini beberapa tata cara dan adab makan yang dianjurkan oleh Nabi Muhammad SAW: pertama, membaca basmalah (بسم اللّة) sebelum makan, danjika lupa maka membaca: بســ اللّه أولـه وآخــره

"Dengan menyebut nama Allah pada awal dan akhirnya"; kedua, duduk dengan baik tegap dan tidak menyandar, karena hal itu lebih baik bagi lambung sehingga makanan akan turun dengan sempurna. Dan Rasulullahshallallahu alaihi wa sallam telah melarang kita untuk makan sambil bersandar

$$
\text { قال رسول اللّه صلى اللّه علية وسلم : أنا لا آكل متكئاً (رواه البخاري) }
$$

Beliau bersabda: "Sesungguhnya aku tidak makan dengan bersandar"; ketiga Mencuci tangan sebelum makan, sebagaimana yang dianjurkan oleh Rasulullah SAW. Keempat, menggunakan tangan kanan; kelima, bersikap sederhana dan tidak berlebih-lebihan ketika makan; keenam, memulai makan dari yang dekat dan tidak memenuhi mulut dengan makanan yang banyak; ketujuh, tidak banyak bicara ketika sedang makan; kedelapan, disunnahkan untuk makan secara berjamaah dan tidak berpencar sendiri-sendiri, karena jamaah akan mempererat persaudaraan dan menyebabkan turunnya barokah pada makanan kita; kesembilan, ketika makan berjamaah dalam satu tempat makan maka jangan mengembalikan apa yang tersisa ditangan ke tempat makan, akan tetapi ambilah suapan yang sedikit hingga tidak bersisa; kesepuluh, tidak mengeluarkan suara keras ketika mengunyah makanan, karena hal itu mengganggu orang lain; kesebelas, jangan mengawasi dan melihat-lihat orang yang sedang makan, karena hal itu mengganggu perasaan mereka, dan mengurangi selera makan; kedua belas, tidak menyisakan makanan dipiring, bahkan kita dianjurkan untuk membersihkan tangan dan jari-jari kita dengan mulut 
ketika selesai makan,dan jika ada makanan yang jatuh supaya dipungut dan dibersihkan kemudian dimakan; ketiga belas, membaca hamdalah dan doa setelah makan:

$$
\text { الحمد الله الذي أطمني هـا ورزقنيـه هـن غـير حسول مـني ولا قـوة }
$$

Segala puji bagi Allah yang telah memberiku makanan ini dan menganugerahkannya kepadaku tanpa susah payah; keempat belas, mencuci tangan setelah makan.

Inilah beberapa tuntunan Rasulullah shallallahu alaihi wa sallam. Dalam makan dan minum.

Di antara perintah agar menjaga kesehatan, juga terdapat larangan melakukan sesuatu y ang dapatmerusak badan akibat tindakannya sendiri (QS. al Baqarah: 195) atau orang lain, seperti ditegaskan dalam hadis yang kemudian dijadikan sebagai salah satu kaidah fiqhiyyah, yaitu: "لا ض-رد و لا ضسرائ.

Hak badan harus dipenuhi, sepert makan jika lapar, minum jika haus, beristirahat jika letih, membersihkan jika kotor, mengobati jika sakit, dan lain-lain. Di samping memberi tuntunan, Nabi juga mencontohkan mengatur pola hidup sehat dan membiasakannya, misalnya, tidur pada permulaan malam setelah shalat Isya', bangun pada tengah malam dan tidur lagi hingga menjelang subuh. Tidur dalam posisi tubuh miring ke kanan, menghadap kiblat dan tidak memenuhi perutnya dengan makanan dan minuman (al Asqollani, 1990: II-109) Dengan posisi demikian, berarti melonggarkan liver dan tidak membebani jantung.

Dengan demikian dapat dipahami, bahwa syariat Islam sangat menekankan pengaturan pola makan yang sehat. Hal-hal yang berhubungan dengan makanan, minuman termasuk obat-obatan diatur secara detail, agar terhindar dari berbagai kesulitan yang akan berdampak buruk pada badan dan yang lainnya. Semuanya itu menunjukkan bahwa ajaran Islam jika dilaksanakan secara konsisten dan benar, maka akan terbukti sejalan dengan konsep hidup sehat, sebagaimana dituntut dalam ilmu kedokteran dan kesehatan. 


\section{Metode Penelitian}

Metode pembahasan yang digunakan dalam penelitian ini adalah metode deskriptif analisis. Peneliti memaparkan hikmahhikmah yang terkandung dalam hadis-hadis etika makan yang telah dikaji melalui aspek kesehatan sebagai pendekataannya, ditambah dengan penjelasan yang terdapat dalam syarh kitab-kitab hadis dan referensi terkait.

Proses pengumpulan data dalam penelitian ini akan dilakukan dengan langkah-langkah sebagai berikut: Langkah pertama, peneliti menghimpun hadis-hadis yang berkaitan dengan آداب الطعام sebagaimana terdapat dalam al kutub al tis'ah sebagai sumber primer, khususnya hadis-hadis yang sangat berkaitan dengan bidang kesehatan atau yang dapat diteliti dan dikaji dari aspek ini; Langkah kedua, hadis tersebut dikaji dan diteliti dengan menggunakan pendekatan ilmu kesehatan; Langkah ketiga, kajian diklasifikasikan secara tersendiri sesuai dengan sub bahasan yang terkait dengan organ-organ tubuh manusia tertentu yang sangat berkaitan dengan proses makan ataupun pencernaan; Langkah keempa, jika data dinilai kurang valid, maka dilakukan uji validitas, dengan menggunakan tes laboratorium. Hal ini dilakukan semata untuk mendapatkan hasil yang valid; Langkah kelima, selain sumber primer, penulis juga mengumpulkan data-data sekunder yang diambill dari buku-buku dan artikel terkait yang termuat dalam jurnal, karya ilmiah, maupun situs internet. Mengingat bahan-bahan yang dibutuhkan sangat banyak termuat dalam situs tersebut; Langkah keenam, mengambil dalam pernyataan dan penjelasan para ahli yang berkompeten dalam bidang kesehatan, fisiologi ataupun anatomi tubuh manusia.

\section{Pembahasan Hasil Penelitian}

Dari beberapa hadis yang kami teliti, didapatkan beberapa hikmah yang terkandung dalam hadis-hadis etika makan yang telah diajarkan oleh Rasulullah SAW, diantaranya: 
a. Membaca Basmalah. Membaca basmalah sebelum makan dapat menghindarkan diri dari penyakit. Karena bakteri dan racun membuat perjanjian dengan Allah SWT, apabila dibacakan basmalah maka mereka akan musnah dari sumber makanan itu.

b. Makan dengan tangan kanan. Cara Rasulullah makan adalah dengan memasukkan makanan dengan tangan kanannya kemudian mengunyahnya sejenak, kemudian mengambil sedikit garam menggunakan jarinya, lalu menghisap garam itu, kemudian baru mengunyah keseluruhannya. Hikmahnya, ternyata kedua belah tangan kita mengeluarkan 3 macam enzim, konsentrasi di tangan kanan lebih banyak daripada yang kiri. Enzim tersebut adalah enzim yang menolong proses pencernaan (digestion).

c. Posisi duduk. 1) tidak bertumpu pada tangan dan juga tidak tengkurap. Hadis ini menjelaskan larangan makan sambil bertumpu pada satu tangan atau sambil tengkurap. Larangan ini mengandung hikmah, di antaranya: đapat menggangu proses masuknya makanan ke lamiuing dan dikhawatirkan akan menimbulkan gangguan pada rongga dada, serta dapat menyebabkan perut menjadi buncit, 2) duduk dengan kaki dilipat. Posisi duduk seperti ini akan sedikit menekan lambung. Tujuannya agar kita dapat berhenti makan sebelum lambung terisi penuh, karena posisi ini secara tidak langsung menjadikan kita merasa kenyang sebelum lambung terisi penuh. Selain itu, penuhnya lambung karena makanan akan berdampak pada menurunnya energi kita dalam beraktivtas.

d. Porsì makanan. Secukupnya tidak terlalu kenyang (sekedar kuat untuk beraktivitas dan tidak sepenuh perut) porsi makan hendaknya dibatasi. Kapasitas perut hendaknya dibagi menjadi tiga bagian, yaitu sepertiga untuk makanan (zat padat), minuman (zat cair), dan udara (gas). Hikmah dari anjuran ini di antaranya untuk menghindarkan kita dari berbagai penyakit yang ditimbulkan akibat dari porsi makan yang melebihi kebutuhan tubuh, di antaranya diabetes. Di sisi lain, porsi yang melebihi kapasitas akan monyebabkan meluberny makanen torar lambung, 
sehingga mengakibatkan gangguan terhadap organ tubuh yang lain.

e. Larangan meniup makanan. Rasulullah SAW. mengajarkan kita untuk minum dengan duduk dan melarang kita untuk minum dari tempat/wadah yang besar. Beliau juga melarang kita bernafas ketika sedang minum. Karena apabila kita minum dari tempat yang besar, kita tentu akan bernafas dan menghembuskan nafas. Apabila kita menghembuskan nafas, kita akan mengeluarkan CO2 (karbondioksida), yang apabila bercampur dengan air ( $\mathrm{H} 2 \mathrm{O})$ akan menjadi $\mathrm{H} 2 \mathrm{CO} 3$ (cuka), sehingga menyebabkan minuman itu menjadi acidic (asam). Hal ini berlaku juga jika kita meniup air yang panas. Makanan/minuman panas sebaiknya dikipas saja dan bukan ditiup. Sedangkan cara minum adalah dengan seteguk-bernafas, seteguk-bernafas sampai habis.

f. Meneguk 3 kali saat minum (berhenti untuk bernafas). Minum dengan cara seperti ini akan lebih mampu menghilangkan haus dari pada minum sekaligus habis. Di sisi lain, menghindarkan dari kemungkinan tersedak.

g. Makan dengan tiga jari. Dalam hadis ini sebenarnya titik tekannya bukan pada jumlah jari yang digunakan untuk makan, namun lebih ditujukan pada porsi makanan yang dimasukkan dalam mulut. Makan dengan menggunakan tiga jari otomatis jumlah makanan yang masuk relatif lebih sedikit daripada makan dengan menggunakan lima jari. Semakin sedikitjumlahnya akan semakin sempurna proses pengunyahan makanan dalam mulut. Hal ini pada gilirannya akan meringankan beban lambung dalam mengolah makanan dalam perut.

h. Tidak berdiri tatkala makan dan minum. Air yang masuk dengan cara duduk akan disaring oleh sfringter. Sfringter adalah suatu struktur maskuler (berotot) yang bisa membuka (sehingga air kemih bisa lewat) dan menutup. Setiap air yang kita minum akan disalurkan pada 'pos-pos' penyaringan yang berada di ginjal. Jika kita minum berdiri, air yang kita minum masuk tanpa disaring lagi dan langsung menuju kandung kemih. Ketika langsung me- 
nuju kandung kemih, maka terjadi pengendapan di saluran ureter. Akibatnya, banyak limbah yang menyisa di ureter. Inilah yang bisa menyebabkan penyakit kristal ginjal yang merupakan salah satu penyakit ginjal yang berbahaya dan susah kencing.

i. Makan dengan tenang tidak tergesa-gesa dan mengunyah makanan dengan sempurna. Cara makan seperti ini akan menghindarkan tersedak, tergigit, kerja organ pencernaan pun jadi lebih ringan. Makanan pun dapat dapat dikunyah lebih baik, sehingga kerja organ percernaan bisa berjalan dengan sempurna. Makan yang tidak dikunyah dengan baik akan sulit dicerna. Dalam jangka waktu lama, bisa menimbulkan kanker usus besar.

Pencernaan yang baik, jika kita makan dengan pelan, kita dapat mengunyah makanan secara sempurna. Banyak pesan agar kita mengunyah makanan sebanyak 32 kali sebelum ditelan. Ini dapat membuat pencernaan kita menjadi lancar. Karena sudah dikunyah dengan sempurna di dalam mulut, usus halus tidak perlu bersusah payah menguraikan makanan lagi untuk menyerap sari-sari makanan. Dengan ini, pencernaan menjadi lebih baik.

Manfaat mengunyah juga diungkapkan oleh para pakar kesehatan di Amerika yang sejak lama telah mengumumkan hasil penelitiannya, yakni anak-anak yang biasa mengunyah lebih lama, cenderung memiliki gigi yang lebih bersih dan kuat. Resiko terserang penyakit gigi bagi mereka relatif kecil. Ditambahkan pula bahwa, mengunyah dalam waktu yang lama dari jenis makanan nabati, khususnya buah-buahan, akan menunjang kesehatan gigi.

Air liur mengandung beberapa zat, termasuk kalsium yang dapat membentengi email gigi dari kerusakan. Dengan begitu, kesehatan gigi akan lebih terjaga. Bahkan, ada sebagian pakar kesehatan gigi yang berpendapat mengunyah buah-buahan selama lima menit, lebih baik dan efektif daripada menggosok gigi. Tentunya anggapan pakar kesehatan itu bukan bermaksud bahwa orang yang sudah mengunyah buah-buahan tidak perlu menggosok gigi. 
Mengunyah dapat merangsang kelenjar ludah untuk mengeluarkan isinya sehingga menyebabkan efek self cleansing yang melarutkan plak dan sisa makanan di dalam mulut. Sebagai bonus kegiatan mengunyah juga dikatakan dapat meningkatkan memory, karena pada saat mengunyah denyut jantung meningkat hal ini menyebabkan oksigenasi otak bertambah sehingga meningkatkan daya ingat.

\section{Simpulan}

Dengan melihat hasil peneliian di atas, dapat kami simpulkan bahwa: dengan memperhatikan tata cara makan yang diajarkan oleh Rasulullah SAW. melalui hadis-hadisnya akan memberikan dapak positif bagi kesehatan kita.

Tatacara yang benar seperti makan dengan tangan kanan dan posisi duduk yang tepat akan memperlancar proses pencernaan dan menghindarkan rasa kekeyangan yang akan berdampak pada menurunnya kualitas aktifitas kita mengunyah dengan sempurna juga memiliki peran dalam menjaga kesehatan lambung dan gigi. Dengan lebih banyak mengunyah menghirdarkan dari resiko penyakit gigi bahkan dapat memperkuat gigi.

Mengunyah Cara makan seperti ini akan menghindarkan tersedak, tergigit, kerja organ pencernaan punjadi lebih ringan. Makanan pun dapat dapat dikunyah lebih baik, sehingga kerja organ percernaan bisa berjalan dengan sempurna. Makan yang tidak dikunyah dengan baik akan sulit dicerna. Dalam jangka waktu lama, bisa menimbulkan kanker usus besar.

Demikian pula dengan porsi makan yang tepat, yaitu dengan membagi menjadi tiga bagian zat padat, zat cair dan gas berguna untuk menghindarkan kita dari berbagai penyakit diantaranya diabetis.

Kajian hadis dengan melihat dari aspek hikmah memang belum banyak dilakukan, baik hikmah dari aspek kesehatan maupun dari aspekyang lain. Maka dari itu, penelitian semacam ini perlu 
untuk diintensifkan dengan tujuan untuk menggali rahasia dan hikmah yang selama ini masih tersembunyi.

Penelitian yang kami lakukan ini masih bersifat mendasar, maka akan lebih baik jika penelitian ini dapat ditindaklanjuti dengan penelitian lintas disipliner, misalnya dengan melibatkan langsung tim dokter atau ahli bidang kesehatan dengan tes labolatorium. Hal itu dilakukan untuk mendapatklan hasil yang lebih akurat.

\section{Daftar Pustaka}

Abdul Aziz, Muhammad bin Syayi. 1997. Al Wigayat wa al 'ilaj bi al Kitab wa al Sunnah. Riyadh: Dar al Faizin.

Abdullah, Muhammad Mahmud. 1989. Al Thib al Qurani Ghidza' wa Dawa'. Beirut: Dar al Kutub al 'Ilmiyah.

Akbar, Ali. 1974. Kesehatan dalam Islam. Jakarta: Fajar Shadiq.

Alwani, Abdullah. 1992. Tarbiyah al Auiad fi al Islam. Bairut: Dar al Salam.

Asqailani, ibnu Hajar al. 1990. Fath al Bari fi Syarh al Shohih al Bukhari. Bairut: Dar al Kutub al Ilmiyyah.

Azraq, Ibrahim bin Abdurrahman ibnu Abi Bakar a1. 1990. Tashil al Manafi fi al Thibb wa al Hikmat. Istanbul: Maktabah al Haqiqat.

Baghdadi, Muwaffiq al Din al.1986. Al Thibb min al Kitab wa al Sunnah. Beirut: Dar al Ma'rifah.

Browne, Edward C dan Iqbal, Muhammad. Rahasia Pengobatan Secara Islum. Terjemahan oleh Bambang Udoyono. 2002. Jakarta: Inofasi.

Bukhari, Muhammad bin Ismail al. 1987. Shahih al Bukhari. Bairut: dar al ibnu Katsir.

Dzahebi al. 1990. Al Thibb al Nabawi. Kairo: Muassasah al Halabi wa Syirkah.

Ethel Sloane. 2004. Anatomi dan Fisiologi. Jakarta: EGC. 